\title{
Research on Design Innovation of Dormitory Furniture in Colleges and Universities
}

\author{
Huaqing Wang ${ }^{1, \text { a }}$ \\ ${ }^{1}$ Leshan Normal University, Sichuan, Leshan, 614000 \\ ${ }^{\mathrm{a} e m a i l,}$
}

Keywords: College Dormitory; Furniture Design; Innovation Research

\begin{abstract}
Personalization is the foundation of design. College bedroom furniture should design from the perspective of student personality needs, in order to create good furniture for students. This paper analyzes the background and problems of the design of bedroom furniture in colleges and universities, summarizes the principles of bedroom furniture design, puts forward the innovative optimization method, and hopes to provide valuable reference for the design of bedroom furniture in colleges and universities.
\end{abstract}

\section{Introduction}

Furniture as a representative of the interior design, always adhere to the "people-oriented" design ideas, committed to the use of beautiful human nature, full-featured furniture for people to bring the best life experience. For a long time, in all kinds of furniture design cases, the bedroom furniture design has not been the design industry's full attention. Dormitory is an important part of the life of college students, students spend most of their time in the bedroom, it is closely linked with the student life and bedroom furniture design level will directly affect the future development of students. University bedroom furniture design issues, it is worth all the furniture design practitioners attaches great importance to how the design of college bedroom furniture innovation is worthy of attention.

\section{The Bedroom Furniture Design Background and Problems}

Background. Research shows that the current domestic college bedroom area is generally 20 to 30 square meters, mostly 4 to 8 people, of which 4, 6 people.

Bedroom furniture, including bed, desk, wardrobe, the pattern is usually two: one is the upper and lower one, that is, above the bed, the following is the desk and wardrobe; one is left and right separation, that is, on the side of the shelf bed, one side is the desk, next to the number of wardrobe, where the desk is divided into two kinds, one is a stand-alone desk, one is the whole type of public long table.

In addition to bed, desk, wardrobe, part of the bedroom will increase the placement of toiletries, lockers, and some colleges and universities also have two public rooms room. In addition to metal bed frame, most of the furniture production materials are common on the market plate, not easy to deformation, easy disassembly.

Desk size and bed size, furniture size will affect the convenience of the bedroom channel. After a series of changes, the college dormitory finally formed the current status of the furniture design, basically able to achieve student life, rest, sleep, learning function.

The Problem. In the past, the process of domestic traditional college life is relatively fixed, during the day in the classroom lectures, afternoon to the library, three meals a day in the cafeteria to eat at night to return to the dormitory, entertainment $\bullet 100$ people generally shallow level of awareness of the bedroom, that Just "sleep, rest" place, so as long as the environment is quiet, strong furniture, to meet the basic physiological needs of students sleep, then generally no longer be other aspects of improvement. However, in the current information society, college students not only have high demand for material needs, but also attaches great importance to spiritual needs, they are good at using the network, prefer to use computers, like sharing and exchange, pay 
attention to personal privacy protection, the pursuit of high quality of life, changes in behavior habits make more and more old bedroom furniture design cannot meet the expectations of contemporary college students, a single model, space boring bedroom furniture design there are many urgent problems to be solved.

Color monotone. The walls and roofs of the university dormitories are basically painted white paint. The ground material is dominated by tiles and terrazzo, and the colors are dark gray. In this kind of indoor environment design tone, the bedroom furniture in the color is usually yellow plate, with milky yellow, brown-based, giving old, dull, old-fashioned visual experience and different functions of the furniture is not color distinguish or decorate the design. Color processing is relatively simple, monotonous, does not meet the student group young and dynamic personality expression do not match the contemporary students to pursue the beauty and personality of the psychological characteristics.

Single function. The primary role of furniture is to have the function. Bedroom furniture due to small indoor area, the furniture function requirements are relatively higher. At present the college bedroom furniture as a combination of fixed, storage space is very small, the students cannot put the large luggage compartment lockers, can only be exposed. The depth of the bookcase is about 60 centimeters, the desktop computer is gradually being replaced by a portable computer and the previous placement of the desktop computer monitor, the host of the location of the space is gradually becoming outdated. Open the wardrobe, usually the lack of internal space corresponding to the functional area separated, the four seasons clothes is not enough and placed in no order, winter large pieces of clothing cannot be properly placed, when clothes are easy to mess up clothes - many furniture in the function. The design of the existence of planning is not in place, not comprehensive, disorderly, simple design of a simple phenomenon.

Lack of human design. In addition to a single function, the current bedroom furniture in the details of the treatment is lack of human considerations. For example, the vast majority of bunk beds and part of the bed of the bed are vertically erected, fixed on the ground, the ladder transverse section of the ladder made of smaller steel pipe, people inclined to climb the body when the foot, and Winter climbing cold feet, there is a certain risk. The upper bed guardrail is made of several iron pipes, and small items near the bed are easy to fall and cause the students to sleep inconvenient. In addition, the upper beds are not provided with shading curtains, lack of privacy when sleeping, and are also susceptible to glare lighting.

Lack of public and private space. College students are in the process of growing the most influential youth, they love the public places to communicate with people, on the one hand also eager to maintain self, with secret personal space. The current design of the bedroom furniture cannot meet the students on the public and private space of the different requirements, the confusion of the interior design of the lack of public and privacy guarantee, for the upper and lower shelf bed, when other students into the bedroom, there is no public space, it is easy to sit on the bed of students, serious pollution of others bed hygiene, violations of private space.

\section{The School Bedroom Furniture Design Principles}

As a kind of daily necessities, furniture design work around the user to start, in the face of "students" the use of groups, college bedroom furniture design must fully consider the following principles:

Functional. Function is the furniture design the primary consideration of the necessary elements, bedroom furniture design must first meet the needs of various types of students to ensure that furniture is easy to use, solid, durable and comfortable, easy to organize and clean.

Comfort. Color, color, color and so on. Students relax and sleep quickly.

Gender. Boys and girls because of the existence of gender differences, it has a different life needs. Designers should take full account of boys love sports, girls love the makeup of the gender needs, accordingly corresponding to the gender of the furniture design.

Privacy. College students are in the important stage of psychological construction, college dormitory living so that they are very important to life in the independence and privacy needs to use 
private space to separate themselves from others, to avoid being observed by others.

Regional. Each place has a unique lifestyle and aesthetic way, the difference between regional culture determines the different regions of the product design for the product has a different style preferences and functional requirements. College bedroom furniture not only from the appearance of regional culture, in the processing methods, materials applications, but also reflect the impact of different regional culture under the furniture design features.

\section{The Innovation Initiatives of Colleges and Universities Bedroom Furniture Design}

In view of the current problems in the design of bedroom furniture in colleges and universities, many colleges and universities in the country have realized that they should fully learn the lessons of failure in the past, re-understand the advanced design concept of bedroom furniture, and make use of humanized innovative measures to create comfortable and convenient for students of the living environment.

The Appearance Innovation. Modern furniture, a wide variety of materials, for college students, the most suitable or wood furniture, wood texture natural, warm texture, can easily create a sense of monks. In the furniture with color, try to choose the purity and lightness of the elegant and stable colors, such as light blue, light green, beige, etc., can ease the mental stress, to eliminate student stress. Furniture modeling by the functional decision, the bedroom furniture design should be simple, fresh and modern style, emphasizing the functional design, smooth lines simple and not simple, different functional areas of color contrast and not glare, both can save manufacturing costs , But also make indoor transparent and bright, simple and leisure.

Functional Innovation. Storage function is the focus of bedroom furniture design. In order to solve the problem of storage space is generally inadequate, bedroom furniture can be optimized as follows: First, for students, especially girls love bedside books, debris habits can be designed in the sleeping side of the mini lockers, push-pull cabinets After the cover is pulled out is a bedside table, you can place the computer, books and so on. Second, the rational use of the desk inside the wall by the wall, where the design of push-pull bookshelves, books and other items need to store bookshelves can be pulled out, when not folded on, the rational use of the furniture inside the space, capacity. Third, the ladder can be designed into a vertical counter cabinet, a multi-purpose, both through the organs fixed into a spiral staircase to facilitate students to climb the upper shop, but also become a locker, increase storage space.

College boys are in the energetic growth period, according to their physiological needs, can be in the boys bedroom through the furniture design into a convenient and simple sports device to increase the boys indoor sports space. For example, at the top of the seat above the bed bar, increase the horizontal bar handle device, in the bed bare left and right side to increase the improved version of the climbing frame, easy for students to carry out simple physical exercise. Girls will have to increase the function of innovation to increase the types of storage space, such as make-up area, jewelry area, decorative area, etc., so the furniture design to expand the storage space, suitable for girls to dispose of different sizes of bottles and jars cans, pick up quickly and easily, will not cause regional chaos. As for the decorative area, you can in the desk wall, bed guardrail and other places placed to increase the hanging dolls and other ornaments of the shelf, in order to meet the individual needs of college girls love decoration.

Space Innovation. College students because of psychological development reasons, the bedroom public and private space has a common demand. In a limited bedroom space to create a shared area, the general need to create a modular combination of furniture to create, for example, more combinations of chairs, after folding can be a suitable for the activities of a large table, furniture, a cabinet through the combination can be a small seat and so on. When you do not need to interact, you can chair, cabinet back to the original state, the formation of hidden space, flexible and free.

In the private area of space creation, you can through the desk side of the folding structure design to avoid the bedroom light, sound interference, to achieve independent, semi-enclosed space construction. First of all, the right side of the desk designed to fold the desktop, the desktop can be 
folded after the space to accommodate the next chair can be installed in the desk outside the shade. But need a separate private space, only need to fold the desktop folded, sitting in the desk and the closet between the space, and pull the curtain, which formed a sound insulation, dark, comfortable, quiet semi-closed space to avoid other types of student activity disturb, improve learning efficiency.

The Details Innovation. In the bedroom furniture design, there are many details of the designer is worth thinking, continuous innovation, to give students a better experience. Many students like to read books before going to bed, based on this habit, you can design on the bed placed in the bedside lamp position, or directly installed with light and bright bed lighting, easy to students lighting. In addition, the top of the desk (bed floor) location can also be designed with lighting to facilitate the daily needs of students.

Many beds without bed screen, students can only pad in the back pad, based on this, the designer can design a half-lying for the bed screen, easy to support the back of the students to protect, half lying comfortable. In many people ignore the mattress design, but also innovative, user-friendly in accordance with the human body curve to fit the physical needs of the mattress, research and development of the appropriate thickness and material, thereby improving the quality of sleep. The upper fence can be changed in the past vertical, designed as horizontal fence, while the fence designed for the groove type, you can put some small objects, increase storage space, easy for students to sleep when the commonly used items. To solve the problem of being criticized for climbing, it is possible to design a step-by-step ladder by widening, while adding a non-slip design on the steps to facilitate students to get out of bed, safe and secure, comfortable and convenient. In view of the problem of sheltering the upper bed without curtains, in the design of the bed, according to the use of habits in advance to design a hanging curtains, such as the bed on the left and right sides of the bed bar set holes, curtain rope, Hook, to form a rolling chute, fixed bed curtain.

\section{Conclusion}

The importance of student education and healthy life makes the furniture facilities of college dormitory more complete, functional design requires higher, more attention to the spiritual needs of students, the environment quality of the bedroom has been continuously optimized.

College bedroom furniture design, not a college unit can be completed, it needs colleges and universities, furniture companies and designers work together to assess the situation, attaches great importance to the design of bedroom furniture. The furniture company to continue to introduce the professional design ability of the designer, enhance the ability of innovation and research and development; designers to people as the center, a comprehensive stand in the student's mind thinking, combined with student physiology, psychology and other needs, attention to create furniture quality, enhance the furniture function and design, to create a multi-level exchanges, living space, designed for students to use and the price so that colleges and universities easy to accept high-quality innovative bedroom furniture.

\section{Acknowledgements}

Fund Project: Leshan Teachers College results cultivation project, Research on the Humanized Design of Dormitory Furniture in Colleges and Universities Based on Multi - functional Collection. Number: S16026

\section{References}

[1] Dong Ying.Study on Humanized Design of Domestic College Students' Apartment [D]. Master's Thesis, Shandong University of Architecture, 2010

[2] Guo Jun. College students on the bedroom space needs [J]. Shanxi Architecture, 2007, 10.

[3] Wang Wenning Zhang Yuanqun. On the student apartment furniture design of human nature[J]. Packaging Engineering .2010.31 (6): 22-45. 
[4] Yang Chun. Outstanding space reconstruction of college students dormitory overall furniture design [J.] Journal of Fine Arts .2014 (06)

[5] Han Tian Teng. Modern furniture design form of space aesthetics[J]. Furniture and interior decoration .2005 (05): 13-15. 